\title{
Nursing care of patients after percutaneous balloon dilation of the aortic valve
}

\section{Vesna Mežnar*1, Andreja Kvas ${ }^{2}$}

'University Medical Centre Ljubljana, Ljubljana, Slovenia

${ }^{2}$ University of Ljubljana, Faculty of Health Sciences, Ljubljana, Slovenia
RECEIVED:

October 3, 2016

ACCEPTED:

October 14, 2016

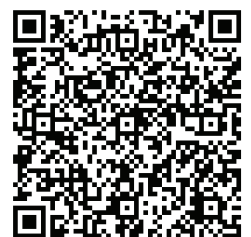

KEYWORDS: nursing care, nurse, aortic valve, elderly, intervention, documentation. CITATION: Cardiol Croat. 2016;11(10-11):562. | DOI: http://dx.doi.org/10.15836/ccar2016.562 *ADDRESS FOR CORRESPONDENCE: Vesna Mežnar, Univerzitetni klinični center Ljubljana, Zaloška cesta 2, 1000 Ljubljana, Slovenia. / Phone: +386-31426550

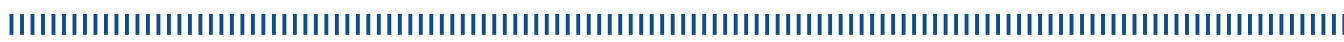
Introduction: The aging population is increasing, thereby the incidence of symptomatic aortic stenosis due to degenerative aortic valve disease in the elderly with comorbidities is also increasing. Therefore, a less invasive percutaneous method was also developed in parallel with the surgical method of treatment of aortic valve stenosis in order to improve the quality of life of the elderly and extension of survival. Percutaneous balloon dilation of the aortic valve serves as a palliative method or bridging to surgical or percutaneous aortic valve replacement.

Purpose: The purpose of this paper is to present comprehensive treatment of patients after percutaneous balloon dilatation of the aortic valve, with a focus on nursing care of the patient before and during percutaneous balloon dilatation.

Methods: The descriptive method of research was used by reviewing domestic and foreign scholarly literature. Resources ware searched using the catalog and bibliographic system COBISS.SI and foreign databases such as CINAHL (Cumulative Index to Nursing and Allied Health Literature), Medline PubMed, Cochrane and Science Direct.

Discussion and Conclusion: The nurse carries out continuous and individually patient-oriented nursing care maintaining the focus on the individual patient. Their work is directed both to anticipating potential complications of an invasive procedure and to preventing them or warning of them properly and professionally together with other medical team members who are involved in the procedure. The patient must be prepared for surgical procedures and nursing care must be provided throughout the procedures. Access to the patient is integrated and based on the following principles: to take responsibility for their work, not harm and be respectful to life and human dignity. All nurse's actions, before and during the procedure, must be recorded in the patient's files.
LITERATURE IIIIIIIIIIIIIIIIIIIIIIIIIIIIIIIIIIIIIIIIIIIIIIIIIIIIIIIIIIIIIIIIIIIIIIIIIIIIIIIIIIIIIIIIIIIIIIIIIIII

1. Krishnaswamy A, Mick S, Kapadia SR. Intraprocedural balloon dilation of the direct flow medical transcatheter aortic valve: First United States experience. Catheter Cardiovasc Interv. 2016 May 19. DOI: http://dx.doi.org/10.1002/ccd.26572. [Epub ahead of print]. 